\title{
Influence of Chitosan Binder on the Adhesion of Silver Nanoparticles on Cotton Fabric and Evaluation of Antibacterial Activity
}

\author{
Nguyen Quoc Hien 1*, Dang Van Phu¹, Nguyen Ngoc Duy', Le Anh Quoc1, Nguyen T. Kim Lan', \\ Hoang T. Dong Quy², Huynh T. Hong Van², Phan Ha Nu Diem³, Tran Thai Hoa ${ }^{3}$ \\ ${ }^{1}$ Research and Development Center for Radiation Technology, Vietnam Atomic Energy Institute, Ho Chi Minh \\ City, Vietnam \\ ${ }^{2}$ University of Science, Vietnam National University in Ho Chi Minh City, Ho Chi Minh City, Vietnam \\ ${ }^{3}$ College of Science, Hue University, Hue City, Vietnam \\ Email: "hien7240238@yahoo.com
}

Received 22 September 2015; accepted 6 November 2015; published 9 November 2015

Copyright (C) 2015 by authors and Scientific Research Publishing Inc.

This work is licensed under the Creative Commons Attribution International License (CC BY).

http://creativecommons.org/licenses/by/4.0/

c) (i) 0pen Access

\begin{abstract}
Colloidal silver nanoparticles (AgNPs) with particle size less than $10 \mathrm{~nm}$ and concentration of 2 $\mathrm{mM} / \mathrm{L}(\sim 200 \mathrm{mg} / \mathrm{L})$ were synthesized by gamma Co-60 ray irradiation of $\mathrm{Ag}^{+} /$chitosan solutions with different chitosan concentration of $0.5 \%, 1 \%$ and $2 \%(w / v)$. Incorporation of AgNPs onto cotton fabric was carried out by padding method with $100 \%$ wet pick-up. The content of AgNPs deposited on cotton fabric and released from cotton fabric after repeated washing was determined by inductively couple plasma-atomic emission spectroscopy (ICP-AES). The results indicated that cotton/AgNPs fabric made from padding into AgNPs solution with $0.5 \%-1 \%$ chitosan was the best one of AgNPs adhesion ability on cotton fabric. Results on antibacterial activity against $S$. aureus showed that cotton/AgNPs fabric with AgNPs content more than $100 \mathrm{mg} / \mathrm{kg}$ exhibited highly antibacterial activity $(\eta>98 \%)$. The mechanical property (tensile strength and elongation) of cotton/AgNPs fabrics was almost unchanged in comparison with untreated cotton fabric. Thus, the resultant cotton/AgNPs fabric with highly antibacterial activity can be potentially used as bed drapes and/or patient uniforms in hospitals, etc.
\end{abstract}

\section{Keywords}

Gamma Co-60 Ray, Silver Nanoparticles, Chitosan, Cotton Fabric, Antibacterial

\footnotetext{
${ }^{*}$ Corresponding author.
}

How to cite this paper: Hien, N.Q., Van Phu, D., Duy, N.N., Quoc, L.A., Lan, N.T.K., Quy, H.T.D., Van, H.T.H., Diem, P.H.N. and Hoa, T.T. (2015) Influence of Chitosan Binder on the Adhesion of Silver Nanoparticles on Cotton Fabric and Evaluation of Antibacterial Activity. Advances in Nanoparticles, 4, 98-106. http://dx.doi.org/10.4236/anp.2015.44011 


\section{Introduction}

The incorporation of silver nanoparticles (AgNPs) into polymers and/or inorganic carriers is of great interest for many researchers because of the potential applications of these nanocomposite materials in medicine [1]-[5], photocatalysis [6] [7], water treatment [8]-[12], textile [13]-[18], etc. More details of the immobilization and practical applications of antibacterial nanoparticles on different carriers can be referred to the paper reviewed recently by Moritz and Geszke-Moritz [19]. It is well known that AgNPs have a broad antibacterial activity while exhibiting low toxicity towards mammalian cells at bacterial killing doses [20] [21]. Nanotechnology has facilitated the production of smaller size of AgNPs with the increase of large surface area-to-volume ratios. It is generally accepted that the smaller the AgNPs size, the stronger the antimicrobial activity [22] [23].

Various methods for the synthesis of AgNPs based on bottom-up approach, i.e. reduction of $\mathrm{Ag}^{+}$ions to $\mathrm{Ag}^{\mathrm{o}}$ (zero-valent silver) in solution have been reported [24] [25] and the most common method is chemical reduction of silver salt precursor using chemical reducing agents [19]. In comparison with other methods, gamma Co-60 ray irradiation has been considered as an effective method with several advantages as described in our previous paper [24]. Chitosan is a natural polysaccharide derived from the deacetylation of chitin with both antibacterial property and biocompatibility [26]. Chitosan has been used as stabilizer in the synthesis of AgNPs by $\gamma$-irradiation method [25] [27] [28]. AgNPs were stabilized by chitosan through simultaneously steric and electrostatic effect by interaction of $-\mathrm{OH}$ and $-\mathrm{NH}_{2}$ groups on the surface of AgNPs. Furthermore, chitosan and AgNPs acted synergistically against bacteria and as a result the AgNPs/chitosan exhibited higher antibacterial activity than any component acting alone [28]. On the other hand, chemical interactions between chitosan and cellulose were reported in chitosan-treated cellulose by diffuse reflectance spectroscopic techniques (UV-Vis and FTIR) [29]. Therefore, chitosan is considered as a suitable binder for the adhesive enhancement of AgNPs with cotton fabric and as an inducer for the synergistic antibacterial activity together with AgNPs for AgNPs/chitosan treated cotton fabric.

In the present study, AgNPs were synthesized by $\gamma$-irradiation using chitosan as both stabilizer and hydroxyl free radical scavenger and the as-synthesized AgNPs stabilized by chitosan were incorporated onto cotton fabric. The influence of chitosan binder on the adhesion of AgNPs on cotton fabric after repeated washing, the antimicrobial activity against Staphylococcus aureus (S. aureus) and the mechanical property of the as-prepared AgNPs/ cotton fabrics were also investigated.

\section{Experimental}

\subsection{Materials}

Analytical grade $\mathrm{AgNO}_{3}$ and lactic acid were purchased from Shanghai Chemical Reagent Co., China. Chitosan made from shrimp shell with deacetylation degree of about $90 \%$ and Mw of $9.2 \times 10^{4} \mathrm{~g} / \mathrm{mol}$ was supplied by Chitosan Co., Vung tau, Vietnam. Bacterium strain namely S. aureus ATCC 6538 was provided by University of Medicine-Pharmacy, Ho Chi Minh City. The Mueller Hinton agar medium for bacterial incubation was purchased from Himedia, Mumbai, India. Distilled water was used in all experiments. Cotton fabric weighting 120 $\mathrm{g} / \mathrm{m}^{2}$ was provided by VICOTEX Company, Vietnam.

\subsection{Methods}

\subsubsection{Synthesis of AgNPs/Chitosan by $\gamma$-Irradiation}

Stock chitosan solution (2\%, w/v) was prepared by dissolving 2 g chitosan in $100 \mathrm{~mL}$ lactic acid solution $1 \%$ (v/v) and stored overnight. Chitosan solution was filtered through stainless steel net (200 mesh) to separate undissolved solid. The desired content of $\mathrm{AgNO}_{3}$ was mixed with chitosan solution to prepare three solutions with $2 \mathrm{mM} \mathrm{Ag}^{+}$and different chitosan concentration of $0.5 \%, 1 \%$ and 2\% (w/v). And then, the prepared $\mathrm{Ag}^{+} / \mathrm{chitosan}^{2}$ solutions were put into glass bottles with plastic caps. The irradiation of $\mathrm{Ag}^{+} / \mathrm{chitosan}$ solutions to prepare AgNPs was carried out on a gamma Co-60 irradiator STSVCo-60/B (Hungary) at VINAGAMMA Center, Ho Chi Minh City with absorbed dose of about 7 kGy [27] [30].

\subsubsection{AgNPs Characterization}

UV-Vis spectra of AgNPs/chitosan solutions which were diluted by water to $0.2 \mathrm{mM}$ were recorded on an UV-2401PC, Shimadzu, Japan and the size of AgNPs was calculated from TEM images taken on a JEM 1010, 
JEOL, Japan [27].

\subsubsection{Incorporation of AgNPs onto Cotton Fabric and Characterization}

Before use, cotton fabric was washed to remove glue then dried and cut into equal-sized square pieces of $0.2 \times$ $0.2 \mathrm{~m}^{2}$. All cotton fabric samples were padded in AgNPs/chitosan solutions of about $5 \mathrm{~min}$. and then squeezed to wet pick-up of $100 \%$. Afterwards, AgNPs treated cotton fabrics (AgNPs/cotton fabric) were air dried under ambient conditions. The silver content in AgNPs/cotton fabric samples was determined by inductively coupled plasmaatomic emission spectroscopy (ICP-AES) on a Perkin-Elmer, Optima 5300 DV. The mechanical property (tensile strength, $F_{b}$ and elongation at break, $\varepsilon_{b}$ ) of AgNPs/cotton fabrics was measured on a Tensile tester Zwick/Roell, Germany following an ASTM method D 5035.

\subsubsection{Washing and Silver Release from AgNPs Incorporated Cotton Fabrics}

The washing process of AgNPs/cotton fabrics was carried out by the process as described by El-Rafie et al. with 5, 10 and 20 washings [17]. The silver content in AgNPs/cotton fabric after washing was also determined by ICP-AES method.

\subsubsection{Antibacterial Activity Tests}

The antibacterial activity of cotton/AgNPs fabrics was tested against $S$. aureus by using a shaking flask as described by Zhang et al. [16] with some modifications. Briefly, $1 \mathrm{~g}$ sample fabric, cut into small pieces with a size of about $0.25 \times 0.25 \mathrm{~cm}^{2}$ was dipped into a flask containing $100 \mathrm{ml}$ of $S$. aureus suspension with a cell concentration of about $10^{6} \mathrm{CFU} / \mathrm{ml}$. The flask was then shaken at $150 \mathrm{rpm}$ on a rotary shaker at room temperature for $24 \mathrm{~h}$. Afterwards, the number of bacteria forming units (CFU) in each mixture sample was quantified by spread plate on Mueller Hinton agar plates and the antibacterial efficiency, $\eta(\%)$ was calculated as follows [16] [27]:

$$
\eta(\%)=100 \times\left(\mathrm{N}_{\mathrm{o}}-\mathrm{N}_{\mathrm{i}}\right) / \mathrm{N}_{\mathrm{o}}
$$

where $\mathrm{N}_{\mathrm{o}}$ and $\mathrm{N}_{\mathrm{i}}$ were the CFU/ml from the original cotton fabric and the AgNPs/cotton fabric, respectively.

\section{Results and Discussion}

\subsection{AgNPs/Chitosan Characterization}

The chitosan stabilized AgNPs solutions with suitably appropriate concentration are protected from aggregation due to both steric and electrostatic stabilization effect of chitosan which has abandon of $-\mathrm{OH}$ and $-\mathrm{NH}_{2}$ groups along the molecular chains [25] [31]. Therefore, colloidal AgNPs/chitosan solution is fairly stable during storage time at ambient temperature [27]. The schematic capping mechanism of AgNPs by chitosan has been proposed by Huang et al. [25]. However, they used rather high $\mathrm{Ag}^{+}$concentration $(\sim 40 \mathrm{mM})$, therefore it caused gelation of $\mathrm{Ag}^{+}$with chitosan during preparation of $\mathrm{Ag}^{+} /$chitosan solution. In our preparation of $2 \mathrm{mM} \mathrm{Ag}^{+}$in $0.5 \%-2 \%$ chitosan solution, no gelation occurred. The synthesis of AgNPs by gamma Co-60 irradiation method, chitosan has been used as a stabilizing and free radial ${ }^{\circ} \mathrm{OH}$ scavenging agent [18] [25] [27]. During irradiation $\mathrm{Ag}^{+}$ion is reduced to $\mathrm{Ag}^{\mathrm{O}}$ atom by $\mathrm{e}_{\mathrm{aq}}^{-}$and $\mathrm{H}^{\circ}$ and $\mathrm{Ag}^{\mathrm{O}}$ atoms will be agglomerated to form AgNPs that are capped by chitosan or by other stabilizers. The detail reducing mechanism of formation of AgNPs by gamma Co-60 irradiation method can be referred to the papers reported by Du et al. [24] and Huang et al. [25]. The UV-Vis spectra of $2 \mathrm{mM}$ AgNPs stabilized by $0.5 \%, 1 \%$ and $2 \%$ chitosan and TEM images with particle size distribution were shown in Figure 1 and Figure 2, respectively. Table 1 summarized the value of optical density (OD), maximum absorption wavelength $\left(\lambda_{\max }\right)$ and average diameter (d) of AgNPs synthesized in different chitosan concentrations.

The obtained results indicated that the AgNPs diameter for three chitosan (CTS) concentrations namely 0.5, 1 and $2 \%$ was not much different from each other in the range of $\sim 7-9 \mathrm{~nm}$. The reason may be due to chitosan was used for stabilization of $2 \mathrm{mM}$ AgNPs with high concentration and already reached to the critical concentration of stabilizer for protecting AgNPs to form the smallest particles size. Du et al. already reported the critical concentration of polyvinyl alcohol for preparation of the smallest size $(\sim 10 \mathrm{~nm})$ of $20 \mathrm{mM}$ AgNPs by gamma Co-60 irradiation was of $2 \%-4 \%$ [32]. 


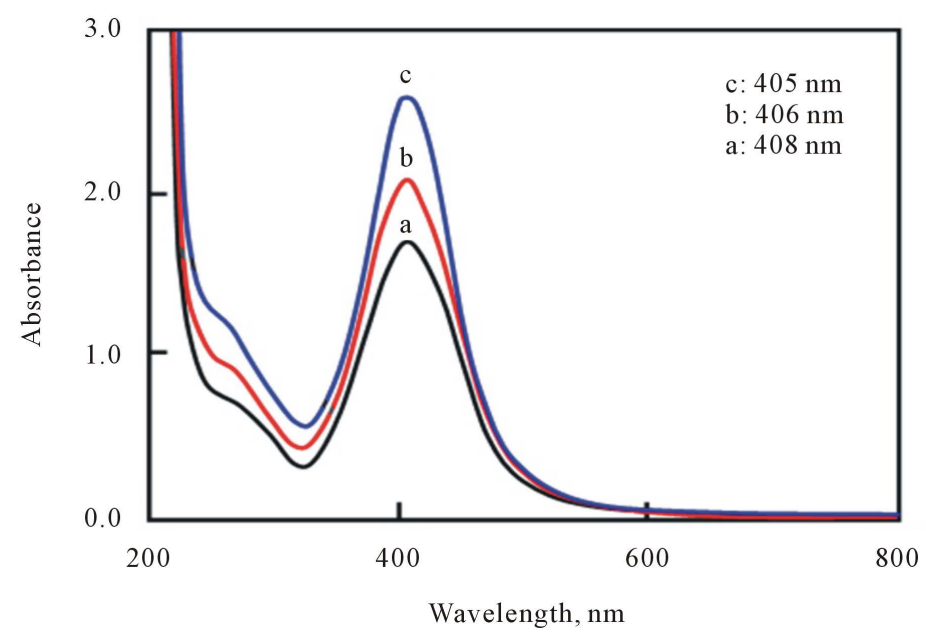

Figure 1. UV-Vis spectra of colloidal AgNPs solutions stabilized with (a) 0.5 , (b) 1 and (c) $2 \%$ chitosan.
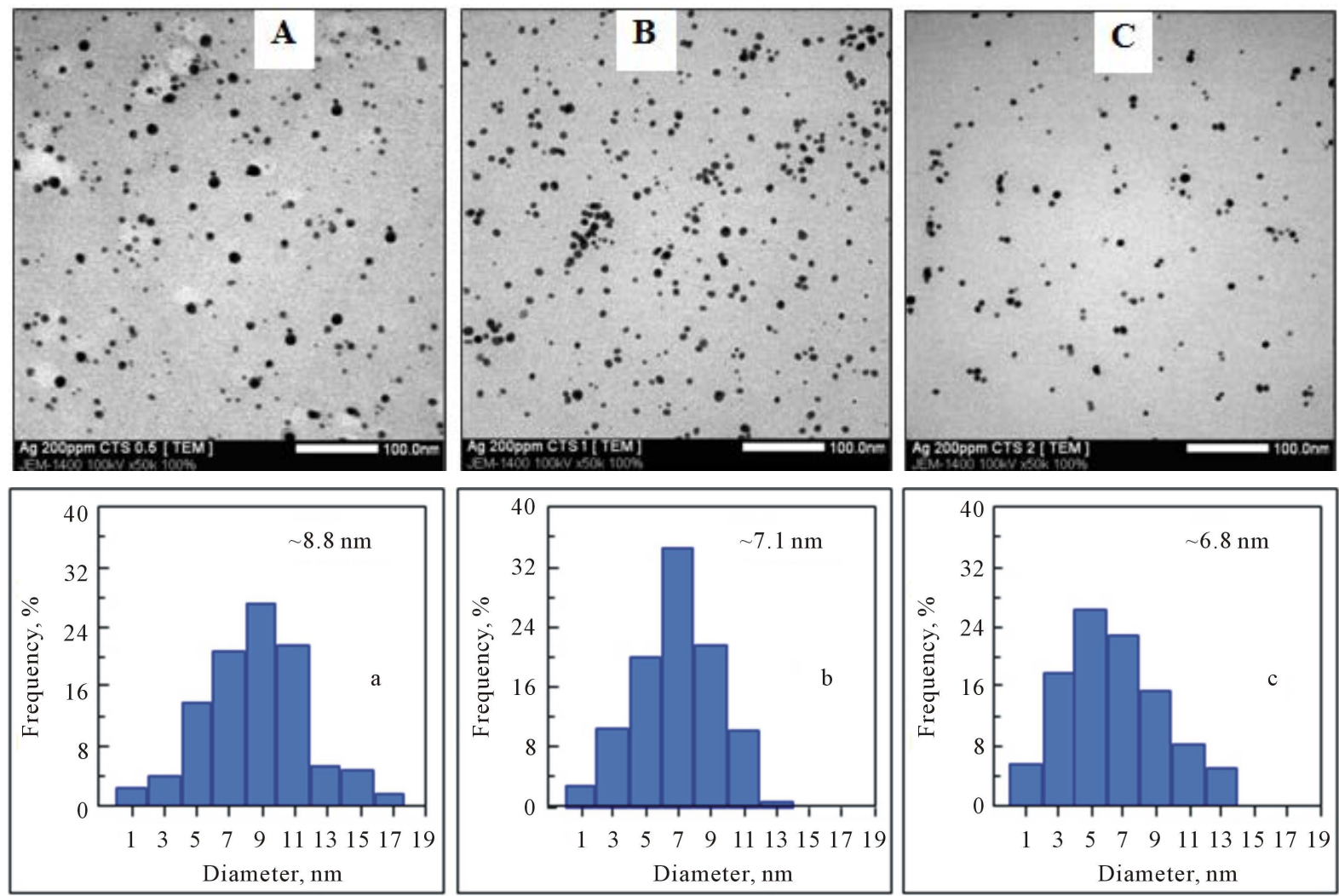

Figure 2. TEM images and particle size distribution histograms of AgNPs stabilized in CTS: 0.5 (A,a), 1 (B,b) and 2\% (C,c).

Table 1. Value of OD, $\lambda_{\max }$ and diameter of AgNPs prepared in different chitosan concentrations.

\begin{tabular}{cccc}
\hline Sample & OD & $\lambda_{\max }(\mathrm{nm})$ & $\mathrm{d}(\mathrm{nm})$ \\
\hline AgNPs 2 mM/CTS 0.5\% & 1.70 & 408 & $8.8 \pm 0.8$ \\
AgNPs 2 mM/CTS 1\% & 2.09 & 406 & $7.1 \pm 0.3$ \\
AgNPs 2 mM/CTS 2\% & 2.58 & 405 & $6.8 \pm 0.5$ \\
\hline
\end{tabular}




\subsection{Silver Release from AgNPs/Cotton Fabric by Washing}

Figure 3 showed the results of silver release from AgNPs/cotton fabric by washings. The obtained results indicated that the suitable concentration of chitosan for better adhesion of AgNPs on cotton fabric was of $0.5 \%-1 \%$. The content of silver release from AgNPs stabilized by 0.5 and 1\% chitosan after 20 washing cycles was of $~ 30 \%$ compared to that of $\sim 44 \%$ for $2 \%$ chitosan sample. It indicated that the higher the binding concentration did not result better adhesion of AgNPs on cotton fabric, particularly in case of chitosan. The reason may be due to excessive chitosan content that could not strongly adhere to cotton fibers, therefore during washing, the excessive portion of chitosan will be easily released and taken AgNPs together with. Further study should be carried out to clarify this phenomenon.

\subsection{Antibacterial Efficiency of AgNPs Coated Cotton Fabrics}

The antibacterial efficiency of AgNPs/cotton fabrics with different content of AgNPs against S. aureus was presented in Table 2 and Figure 4. It can be observed that all the AgNPs/cotton fabrics with silver content from $124 \mathrm{mg} / \mathrm{kg}$ to $245 \mathrm{mg} / \mathrm{kg}$ fabric showed highly antibacterial efficiency (>98\% compared with untreated cotton fabric). The antibacterial efficiency increased slightly from $98.04 \%$ to $99.98 \%$ with the increase of the silver content of AgNPs/cotton fabric. According to the results reported by Zhang et al. [16], the antimicrobial efficiency of AgNPs coated cotton fabric with silver content of about more than $158 \mathrm{mg} / \mathrm{kg}$ fabric against S. aureus was almost to reach to $\eta \approx 100 \%$. The reason of the difference of antibacterial efficiency of Zhang et al. [16] and our result in this work may be due to the cell concentration of $S$. aureus that they used for antibacterial test was of about $10^{6} \mathrm{CFU} / \mathrm{ml}$ which was smaller compared with $10^{7} \mathrm{CFU} / \mathrm{ml}$ in our antibacterial test experiment. The results also indicated that after 20 washing cycles, AgNPs/cotton fabric still maintained highly antibacterial activity.

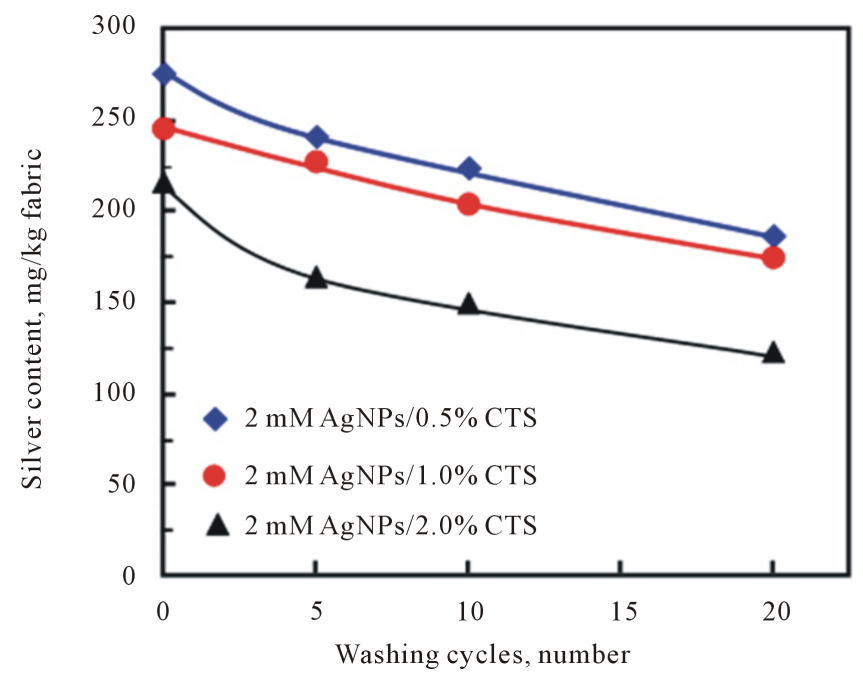

Figure 3. Silver content of AgNPs/cotton fabrics after washing.

Table 2. Silver content and antibacterial efficiency against S. aureus of AgNPs/cotton fabrics.

\begin{tabular}{cccc}
\hline Cotton fabric samples & Silver content (mg/kg fabric) & Surviving cells, (CFU/ml) & Efficiency $(\eta$, \%) \\
\hline Untreated & $0^{(*)}$ & $1.13 \times 10^{7}$ & - \\
1 & 245 & $2.70 \times 10^{3}$ & 99.98 \\
2 & 204 & $1.25 \times 10^{4}$ & 99.89 \\
3 & 177 & $1.35 \times 10^{5}$ & 98.81 \\
4 & 124 & $2.21 \times 10^{5}$ & 98.04 \\
\hline
\end{tabular}

$\left(^{*}\right)$ not detected by ICP-AES (untreated cotton fabric). 


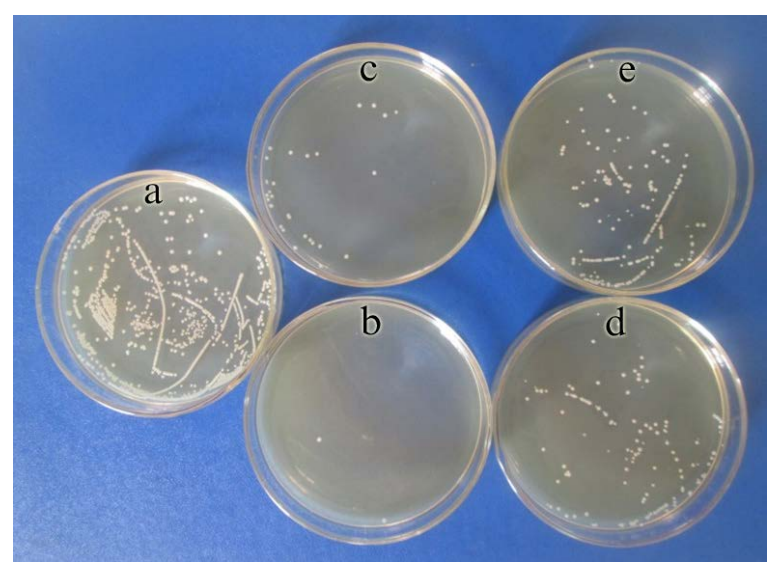

Figure 4. S. aureus colonies forming on agar plates: (a) control (cotton fabric); (b), (c), (d) and (e) AgNPs/cotton fabric with 245, 204, 177 and $124 \mathrm{mg}$ silver/kg fabric, respectively.

Table 3. The value of $F_{b}$ ) and $\varepsilon_{b}$ of cotton and cotton/AgNPs fabrics.

\begin{tabular}{ccc}
\hline Sample & $F_{b}, \mathrm{~N}$ & $\varepsilon_{b}, \%$ \\
\hline Cotton fabric & $299.4 \pm 06.5$ & $24.3 \pm 1.4$ \\
AgNPs/cotton fabric (chitosan 0.5\%) & $289.1 \pm 14.8$ & $21.7 \pm 2.9$ \\
AgNPs/cotton fabric (chitosan 1\%) & $289.9 \pm 09.7$ & $23.3 \pm 1.5$ \\
AgNPs/cotton fabric (chitosan 2\%) & $270.4 \pm 07.4$ & $23.3 \pm 2.8$ \\
\hline
\end{tabular}

In addition, according to our results reported in a previous paper, AgNPs/cotton fabrics are innoxious to skin with coefficient of $k=0$ [18]. Furthermore, concerning environmental impact of AgNPs, it is also worth to note that the AgNPs in wastewater is almost completely transformed into $\mathrm{Ag}_{2} \mathrm{~S}$ that has extremely low solubility and exhibits a much lower toxicity than other forms of silver [33] [34]. Therefore, AgNPs release from AgNPs/cotton fabric into wastewater by washing will be transformed into $\mathrm{Ag}_{2} \mathrm{~S}$ that is considered to have no significant impact to the environment [33]. Therefore, AgNPs/cotton fabric with highly antibacterial activity can be potentially used as bed drapes and/or patient uniforms in hospitals, especially for patients with infectious diseases, etc.

\subsection{Mechanical Property of AgNPs Coated Cotton Fabric}

Table 3 presented the mechanical property particularly tensile strength $\left(F_{b}\right)$ and elongation at break $\left(\varepsilon_{b}\right)$ of cotton and AgNPs/cotton fabrics. As a result, $F_{b}$ and $\varepsilon_{b}$ of AgNPs incorporated cotton fabrics were almost unchanged in comparison with untreated cotton fabric.

\section{Conclusion}

Colloidal AgNPs solution was successfully synthesized by gamma Co-60 irradiation method using chitosan as stabilizer and hydroxyl free radical scavenger. The diameter of $2 \mathrm{mM}$ AgNPs stabilized with $0.5 \%-2 \%$ chitosan was of 7 - $9 \mathrm{~nm}$. AgNPs stabilized with $0.5 \%$ - 1\% chitosan were found to be better adhesion on cotton fabric. Thus, the as-prepared AgNPs/cotton fabric with highly antibacterial activity, low content of silver release by washing and safety can be potentially used as bed drapes and/or patient uniforms in hospitals, etc. Pilot scale production line with $30-50 \mathrm{~m}^{2} / \mathrm{h}$ of AgNPs/cotton fabric by padding method has been carrying out.

\section{Acknowledgements}

The authors are thankful to VINAGAMMA Center, VINATOM for favorable conditions to perform this research. We are also grateful to the contribution of Quy, H.T.D., Van, H.T.H., Diem, P.H.N. and Hoa, T.T. in characterization of materials. 


\section{References}

[1] Silver, S., Phung, L.T. and Silver, G. (2006) Silver as Biocides in Burn and Wound Dressings and Bacterial Resistance to Silver Compounds. Journal of Industrial Microbiology and Biotechnology, 33, 627-634. http://www.ncbi.nlm.nih.gov/pubmed/16761169

[2] Tian, J., Wong, K.K.Y., Ho, C.M., Lok, C.N., Yu, W.Y., Che, C.M., Chiu, J.F. and Tam, P.K.H. (2007) Topical Delivery of Silver Nanoparticles Promotes Wound Healing. ChemMedChem, 2, 129-136. http://www.ncbi.nlm.nih.gov/pubmed/17075952

[3] Jain, J., Arora, S., Rajwade, J.M., Omray, P., Khandelwal, S. and Paknikar, K.M. (2009) Silver Nanoparticles in Therapeutics: Development of an Antimicrobial Gel Formulation for Topical Use. Molecular Pharmaceutics, 6, 13881401. http://www.ncbi.nlm.nih.gov/pubmed/19473014 http://dx.doi.org/10.1021/mp900056g

[4] Lu, S., Gao, W. and Gu, H.Y. (2008) Construction, Application and Biosafety of Silver Nanocrystalline Chitosan Wound Dressing. Burn, 34, 623-628. http://www.ncbi.nlm.nih.gov/pubmed/18226459

[5] Chaloupka, K., Malam, Y. and Seifalian, A. M. (2010) Nanosilver as a New Generation Nanoproduct in Biomedical Applications. Trends in Biotechnology, 28, 580-588. http://www.ncbi.nlm.nih.gov/pubmed/20724010 http://dx.doi.org/10.1016/j.tibtech.2010.07.006

[6] Sobana, N., Muruganadham, M., Swaminathan, M. (2006) Nano-Ag Particles Doped $\mathrm{TiO}_{2}$ for Efficient Photo-degradation of Direct Azo Dyes. Journal of Molecular Catalysis A: Chemical, 258, 124-132. http://www.sciencedirect.com/science/article/pii/S138111690600817X http://dx.doi.org/10.1016/j.molcata.2006.05.013

[7] Oros-Ruiz, S., Zanella, R. and Prado, B. (2013) Photocatalytic Degradation of Frimethoprim by Metallic Nanoparticles Supported $\mathrm{TiO}_{2}$-P25. Journal of Hazardous Materials, 263, 28-35. http://www.sciencedirect.com/science/article/pii/S0304389413002653 http://dx.doi.org/10.1016/j.jhazmat.2013.04.010

[8] Jain, P. and Pradeep, T. (2005) Potential of Silver Nanoparticles-Coated Polyurethane Foam as an Antibacterial Water Filter. Biotechnology and Bioengineering, 90, 59-63. http://onlinelibrary.wiley.com/doi/10.1002/bit.20368 http://dx.doi.org/10.1002/bit.20368

[9] Nangmenyi, G., Yue, Z., Mehrabi, S., Mintz, E. and Economy, J. (2009) Synthesis and Characterization of SilverNanoparticle-Impregnated Fiberglass and Utility in Water Treatment. Nanotechnology, 20, Article ID: 495705. http://www.ncbi.nlm.nih.gov/pubmed/19904023 http://dx.doi.org/10.1088/0957-4484/20/49/495705

[10] Ren, D. and Smith, J.A. (2013) Retention and Transport of Silver Nanoparticles in a Ceramic Porous Medium Used for Point-Of Use Water Treatment. Environmental Science and Technology, 47, 3825-3832. http://www.ncbi.nlm.nih.gov/pubmed/23496137 http://dx.doi.org/10.1021/es4000752

[11] Nguyen, T.A.T., Dang, V.P., Nguyen, N.D., Le, A.Q., Nguyen, D.T. and Nguyen, Q.H. (2014) Bactericidal Activity and Silver Release of Porous Ceramic Candle Filter Prepared by Sintering Silica with Silver Nanoparticles/Zeolite for Water Disinfection. Advances in Natural Sciences: Nanoscience and Nanotechnololy, 5, Article ID: 035001. http://www.academia.edu/11216805 http://dx.doi.org/10.1088/2043-6262/5/3/035001

[12] van Halem, D., van der Laan, H., Heijman, S.G.J., van Dijk, J.C. and Amy, G.L. (2009) Assessing the Sustainability of the Silver-Impregnated Ceramic Pot Filter for Low-Cost Household Drinking Water Treatment. Physics and Chemistry of the Earth, 34, 36-42. http://www.sciencedirect.com/science/article/pii/S1474706508000120 http://dx.doi.org/10.1016/j.pce.2008.01.005

[13] Lee, H.J., Yeo, Y. and Jeong, S.H. (2003) Antibaterial Effect of Nanosized Silver Colloidal Solution on Textile Fabrics. Journal of Materials Science, 38, 2199-2204. http://link.springer.com/article/10.1023\%2FA\%3A1023736416361 http://dx.doi.org/10.1023/A:1023736416361

[14] Lee, H.J. and Jeong, S.H. (2005) Bacteriostasis and Skin Innoxiousness of Nanosize Silver Colloids on Textile Fabrics. Textile Research Journal, 75, 551-556. http://trj.sagepub.com/content/75/7/551 http://dx.doi.org/10.1177/0040517505053952

[15] Perkas, N., Amirian, G., Dubinsky, S., Gazit, S. and Gedanken, A. (2007) Ultrasound-Assisted Coating of Nylon 6,6 with Silver Nanoparticles and Its Antibacterial Activity. Journal of Applied Polymer Science, 104, 1423-1430. http://onlinelibrary.wiley.com/doi/10.1002/app.24728 http://dx.doi.org/10.1002/app.24728

[16] Zhang, F., Wu, X., Chen, Y. and Lin, H. (2009) Application of Silver Nanoparticles to Cotton Fabric as an Antibac- 
terial Textile Finish. Fibers and Polymers, 10, 496-501. http://dx.doi.org/10.1007/s12221-009-0496-8 http://link.springer.com/article/10.1007\%2Fs12221-009-0496-8

[17] El-Rafie, M.H., Ahmed, H.B. and Zahran, M.K. (2014) Characterization of Nanosilver Coated Cotton Fabric and Evaluation of Its Antibacterial Efficacy. Carbohydrate Polymers, 107, 174-181.

http://www.sciencedirect.com/science/article/pii/S0144861714001453 http://dx.doi.org/10.1016/j.carbpol.2014.02.024

[18] Hanh, T.T., Phu, D.V., Thu, N.T., Quoc, L.A., Duyen, D.N.B. and Hien, N.Q. (2014) Gamma Irradiation of Cotton Fabrics in $\mathrm{AgNO}_{3}$ Solution for Preparation of Antibacterial Fabrics. Carbohydrate Polymers, 101, 1243-1248. http://www.ncbi.nlm.nih.gov/pubmed/24299897 http://dx.doi.org/10.1016/j.carbpol.2013.10.069

[19] Moritz, M. and Geszke-Moritz, M. (2013) The Newest Achievements in Synthesis, Immobilization and Practical Applications of Antibacterial Nanoparticles. Chemical Engineering Journal, 228, 596-613. http://www.sciencedirect.com/science/article/pii/S1385894713006669 http://dx.doi.org/10.1016/j.cej.2013.05.046

[20] Wang, H., Wang, J., Hong, J., et al. (2007) Preparation and Characterization of Silver Nanocomposite Textile. Journal of Coatings Technology and Research, 4, 101-106. http://link.springer.com/article/10.1007\%2Fs11998-007-9001-8 http://dx.doi.org/10.1007/s11998-007-9001-8

[21] Rai, M., Yadav, A. and Gade, A. (2009) Silver Nanoparticles as a New Generation of Antimicrobials. Biotechnology Advances, 27, 76-83. http://www.sciencedirect.com/science/article/pii/S0734975008000918 http://dx.doi.org/10.1016/j.biotechadv.2008.09.002

[22] Lu, Z., Rong, K., Li, J., Yang, H. and Chen, R. (2013) Size-Dependent and Antibacterial Activities of Silver Nanoparticles against Oral Anaerobic Pathogenic Bacteria. Journal of Materials Science: Materials in Medicine, 24, 1465-1471. http://www.ncbi.nlm.nih.gov/pubmed/23440430 http://dx.doi.org/10.1007/s10856-013-4894-5

[23] Martínez-Castañón, G.A., Niño-Martínez, N., Martínez-Gutierrez, F., Martínez-Mendoza, J.R. and Ruiz, F. (2008) Synthesis and Antibacterial Activity of the Silver Nanoparticles with Different Sizes. Journal of Nanoparticle Research, 10, 1343-1348. http://link.springer.com/article/10.1007\%2Fs11051-008-9428-6 http://dx.doi.org/10.1007/s11051-008-9428-6

[24] Du, B.D., Phu, D.V., Duy, N.N., Lan, N.T.K., Lang, V.T.K., Thanh, N.V.K., Phong, N.T.P. and Hien, N.Q. (2008) Preparation of Colloidal Silver Nanoparticles in Poly( $N$-vinylpyrrolidone) by $\gamma$-Irradiation. Journal of Experimental Nanoscience, 3, 207-213. http://www.tandfonline.com/doi/abs/10.1080/17458080802353527 http://dx.doi.org/10.1080/17458080802353527

[25] Huang, N.M., Radiman, S., Lim, H.N., Khiew, P.S., Chiu, W.S., Lee, K.H., Syahida, A., Hashim, R. and Chia, C.H. (2009) $\gamma$-Ray Assisted Synthesis of Silver Nanoparticles in Chitosan Solution and the Antibacterial Properties. Chemical Engineering Journal, 155, 499-507. http://www.sciencedirect.com/science/article/pii/S1385894709005385 http://dx.doi.org/10.1016/j.cej.2009.07.040

[26] Xia, W., Liu, P., Zhang, J. and Chen, J. (2011) Biological Activities of Chitosan and Chito-Oligosaccharides. Food Hydrocolloids, 25, 170-179. http://www.sciencedirect.com/science/article/pii/S0268005X10000469 http://dx.doi.org/10.1016/j.foodhyd.2010.03.003

[27] Phu, D.V., Lang, V.T.K., Lan, N.T.K., Duy, N.N., Chau, D.N., Du, B.D., Cam, B.D. and Hien, N.Q. (2010) Synthesis and Antimicrobial Effects of Colloidal Silver Nanoparticles in Chitosan by $\gamma$-Irradiation. Journal of Experimental Nanoscience, 5, 169-179. http://dx.doi.org/10.1080/17458080903383324

[28] Potara, M., Jakab, E., Damert, A., Popescu, O., Canpean, V. and Astilean, S. (2011) Synergistic Antimicrobial Activity of Chitosan-Silver Nanoparticles on Staphylococcus aureus. Nanotechnology, 22, Article ID: 135101. http://www.ncbi.nlm.nih.gov/pubmed/21343644 http://dx.doi.org/10.1088/0957-4484/22/13/135101

[29] Urreaga, J.M. and de la Orden, M.U. (2006) Chemical Interactions and Yellowing in Chitosan-Treated Cellulose. European Polymer Journal, 42, 2606-2616. http://www.sciencedirect.com/science/article/pii/S0014305706001534 http://dx.doi.org/10.1016/j.eurpolymj.2006.05.002

[30] Remita, S., Fontaine, P., Rochas, C., Muller, F. and Goldman, M. (2005) Radiation Induced Synthesis of Silver Nanoshells Formed onto Organic Micelles. The European Physical Journal D, 34, 231-233.

http://link.springer.com/article/10.1140/epjd/e2005-00149-x

http://dx.doi.org/10.1140/epjd/e2005-00149-x

[31] Kvítek, L., Panáček, A., Soukupová, J., Kolář, M., Večeřvá, R., Prucek, R., Holecová, M. and Zbořil, R. (2008) Effect of Surfactants and Polymers on Stability and Antibacterial Activity of Silver Nanoparticles (NPs). The Journal of Physical Chemistry C, 112, 5825-5834. http://pubs.acs.org/doi/abs/10.1021/jp711616v 
http://dx.doi.org/10.1021/jp711616v

[32] Du, B.D., Phu, D.V., Cam, B.D. and Hien, N.Q. (2007) Synthesis of Silver Nanoparticles by $\gamma$-Ray Irradiation Using PVA as Stabilizer. Vietnam Journal of Chemistry, 45, 136-140.

[33] Kaegi, R., Voegelin, A., Sinnet, B., Zuleeg, S., Hagendorfer, H., Burkhardt, M. and Siegrist, H. (2011) Behavior of Metallic Silver Nanoparticles in a Pilot Wastewater Treatment Plants. Environmental Science and Technology, 45, 3902-3908. http://pubs.acs.org/doi/abs/10.1021/es1041892 http://dx.doi.org/10.1021/es1041892

[34] Ratte, H.T. (1999) Bioaccumulation and Toxicity of Silver Compounds: A Review. Environmental Toxicology and Chemistry, 18, 89-108. http://onlinelibrary.wiley.com/doi/10.1002/etc.5620180112 http://dx.doi.org/10.1002/etc.5620180112 